Check for updates

Cite this: RSC Adv., 2019, 9, 11634

Received 7th January 2019

Accepted 3rd April 2019

DOI: $10.1039 / c 9 r a 00145 j$

rsc.li/rsc-advances

\title{
Charge balance control of quantum dot light emitting diodes with atomic layer deposited aluminum oxide interlayers $\uparrow$
}

\author{
Hoseok Jin, ${ }^{a}$ Hyungseok Moon, ${ }^{a}$ Woosuk Lee, ${ }^{a}$ Hyeok Hwangbo, ${ }^{a}$ Sang Heon Yong, ${ }^{a}$ \\ Ho Kyoon Chung ${ }^{b}$ and Heeyeop Chae (D) *ab
}

\begin{abstract}
We developed a $1.0 \mathrm{~nm}$ thick aluminum oxide $\left(\mathrm{Al}_{2} \mathrm{O}_{3}\right)$ interlayer as an electron blocking layer to reduce leakage current and suppress exciton quenching induced by charge imbalance in inverted quantum dot light emitting diodes (QLEDs). The $\mathrm{Al}_{2} \mathrm{O}_{3}$ interlayer was deposited by an atomic layer deposition (ALD) process that allows precise thickness control. The $\mathrm{Al}_{2} \mathrm{O}_{3}$ interlayer lowers the mobility of electrons and reduces Auger recombination which causes the degradation of device performance. A maximum current efficiency of $51.2 \mathrm{~cd} \mathrm{~A} \mathrm{~A}^{-1}$ and an external quantum efficiency (EQE) of $12.2 \%$ were achieved in the inverted QLEDs with the $\mathrm{Al}_{2} \mathrm{O}_{3}$ interlayer. The $\mathrm{Al}_{2} \mathrm{O}_{3}$ interlayer increased device efficiency by 1.1 times, increased device lifetime by 6 times, and contributed to reducing efficiency roll-off from $38.6 \%$ to $19.6 \%$ at a current density up to $150 \mathrm{~mA} \mathrm{~cm}{ }^{-2}$. The improvement of device performance by the $\mathrm{Al}_{2} \mathrm{O}_{3}$ interlayer is attributed to the reduction of electron injection and exciton quenching induced by zinc oxide $(\mathrm{ZnO})$ nanoparticles (NPs). This work demonstrates that the $\mathrm{Al}_{2} \mathrm{O}_{3}$ interlayer is a promising solution for charge control in QLEDs and that the ALD process is a reliable approach for atomic scale thickness control for QLEDs.
\end{abstract}

\section{Introduction}

Colloidal quantum dots (QDs) are attracting attention as a promising light emitting material for optoelectronic devices due to their high color purity, high quantum yield and low cost solution processing. ${ }^{1-3}$ QDs have been widely applied in many applications such as solar cells, light emitting diodes and biological applications. ${ }^{4-8}$ QDs are particularly applicable to display and lighting devices because the emission wavelength can be easily shifted depending on the size, shape, and composition of the QDs. ${ }^{9-13}$ The device performance of the state-of-the-art QLEDs is comparable to that of commercially available organic light emitting diodes (OLEDs). ${ }^{\mathbf{1 4 - 1 7}}$ However, the stability of QLEDs lags behind that of OLEDs and it needs to be overcome for commercialization.

The efficiency and stability of QLEDs are known to be strongly dependent on Auger recombination. ${ }^{18-20}$ Auger recombination, a non-radiative decay process, is an exciton quenching mechanism in which extra carriers absorb exciton energy. The exciton quenching reduces device efficiency, induces efficiency

${ }^{a}$ School of Chemical Engineering, Sungkyunkwan University, Suwon, 16419, Republic of Korea.E-mail: hchae@skku.edu

${ }^{b}$ SKKU Advanced Institute of Nanotechnology, Sungkyunkwan University, Suwon, 16419, Republic of Korea

$\dagger$ Electronic supplementary information (ESI) available. See DOI: 10.1039/c9ra00145j roll-off and shortens device lifetime. Auger recombination is caused by the imbalance of the charge mobility in transport layers. ${ }^{11-14}$ Electron mobility of ZnO NPs electron transport layers (ETL) is known to be faster than the hole mobility of hole transport layers (HTL) in QLEDs. ${ }^{\mathbf{1 4}}$

Several approaches are proposed to enhance the efficiency and stability of QLEDs by controlling electron injection. Adopting composition of QDs, ${ }^{21}$ modifying surface ligands ${ }^{22}$ or introducing extra shell of the core/shell/shell structure of QDs effectively suppress efficiency roll-off behavior. ${ }^{19}$ Various thin interlayers were introduced to improve the charge balance by suppressing electron injection with poly(methyl methacrylate), ${ }^{\mathbf{1 4}}$ polyethylenimine ethoxylated (PEIE) ${ }^{\mathbf{1 5}}$ polyethylenimine (PEI) ${ }^{23}$ polyfluorene derivatives, ${ }^{24}$ and soluble $\mathrm{Al}_{2} \mathrm{O}_{3} \cdot{ }^{22}$ Organic materials are sensitive to oxygen and moisture than inorganic materials and decrease stability of QLEDs. All organic and inorganic interlayers have been formed with solution processes so far. ${ }^{14,15,23,25}$ Thickness control in atomic-scale of interlayer is absolutely important because it forms tunneling barrier in the device. However, it is challenging to control the atomic scale thickness with the solution processes.

In this study, we introduced the inorganic $\mathrm{Al}_{2} \mathrm{O}_{3}$ interlayer between ETL and emitting layer (EML) as the electron blocking layer by a spatially-resolved ALD process that allows for a precisely controlled thickness. ALD processes can form thin conformal films and provide good uniformity and precise thickness control. ${ }^{26,27}$ The thickness effect of $\mathrm{Al}_{2} \mathrm{O}_{3}$ interlayer on 
device efficiency and lifetime was investigated in inverted QLEDs.

\section{Experimental}

\section{Inverted QLEDs fabrication}

The device with a conventional structure is not suitable in our work due to QDs degradation by plasma in the spatially-resolved ALD process (Fig. S1 $\dagger$ ). Inverted QLEDs made in this work consists of indium tin oxide (ITO)/ZnO/ $/ \mathrm{Al}_{2} \mathrm{O}_{3} / \mathrm{QDs} / \mathrm{PEIE} /$ poly($N, N^{\prime}$-bis(4-butylphenyl)- $N, N^{\prime}$-bis(phenyl)benzidine (poly-TPD)/ $\mathrm{MoO}_{x} / \mathrm{Al}$ as shown in Fig. $1 \mathrm{a}^{15,33}$ and the band energy levels of each materials are shown in Fig. 1b. UV-visible absorption spectra and ultraviolet photoelectron spectra of QDs, poly-TPD and ZnO NPs are illustrated in Fig. S2 and S3. $\dagger$ A patterned ITO on glass substrate was cleaned sequentially with acetone and methanol. A $70 \mathrm{~nm}$-thick ZnO NPs (80 $\mathrm{mg} \mathrm{ml}^{-1}$, in ethanol) ETL was spin-coated at $1500 \mathrm{rpm}$ for $30 \mathrm{~s}$ and baked at $150{ }^{\circ} \mathrm{C}$. The $\mathrm{Al}_{2} \mathrm{O}_{3}$ interlayers from 0 to $3.0 \mathrm{~nm}$ were deposited on $\mathrm{ZnO}$ NPs layers by a spatially-resolved ALD process. A $25 \mathrm{~nm}$-thick CdSe@ZnS/ZnS QDs (in hexane/octane, OD = 1.5), a $7.5 \mathrm{~nm}$ thick-PEIE (in 2-methoxyethanol, $0.5 \mathrm{wt} \%$ ), a $40 \mathrm{~nm}$-thick polyTPD HTL (in chlorobenzene, $10 \mathrm{mg} \mathrm{ml}^{-1}$ ) and a $10 \mathrm{~nm}$-thick $\mathrm{MoO}_{x}$ hole injection layer (in acetonitrile, $10 \mathrm{mg} \mathrm{ml}^{-1}$ ) were spin-coated at $3000 \mathrm{rpm}$ for $30 \mathrm{~s}$ and baked at $150{ }^{\circ} \mathrm{C}$ sequentially. $\left(\mathrm{MoO}_{3}\right)_{12} \cdot \mathrm{H}_{3} \mathrm{PO}_{4} \cdot\left(\mathrm{H}_{2} \mathrm{O}\right)_{x}(\mathrm{PMAH})$ solution (in acetonitrile, $10 \mathrm{mg} \mathrm{ml}^{-1}$ ) was stirred for $10 \mathrm{~min}$ at $60{ }^{\circ} \mathrm{C}$ and filtered through polyvinylidene fluoride (PVDF) membrane before the spincoating. All layers were deposited and baked in a nitrogenfilled glove box $\left(\mathrm{H}_{2} \mathrm{O}<1 \mathrm{ppm}\right)$. Finally, Al electrodes $(100 \mathrm{~nm})$ were deposited by a thermal evaporation process under high vacuum of $\sim 6 \times 10^{-6}$ torr.

\section{Deposition of $\mathrm{Al}_{2} \mathrm{O}_{3}$ interlayer by spatially-resolved ALD process}

The $\mathrm{Al}_{2} \mathrm{O}_{3}$ interlayer was formed by trimethylaluminum (TMA) as an aluminum precursor and $\mathrm{N}_{2} \mathrm{O}$ plasma as an oxygen radical precursor. TMA with Ar carrier gas and $\mathrm{N}_{2} \mathrm{O}$ plasma are supplied to source and plasma zone. The sequential procedure of spatially-resolved ALD process are shown Fig. 1c. Each zone is separated by adjacent purge zones to prevent gas mixing and the gap between moving substrate and gas supplied head is less than $2 \mathrm{~mm}$. The gas flowrate of TMA precursor with Ar carrier gas and $\mathrm{N}_{2} \mathrm{O}$ precursor are 50 and $20 \mathrm{sccm}$. The $\mathrm{Al}_{2} \mathrm{O}_{3}$ interlayer was deposited on the devices at the substrate temperature of $80^{\circ} \mathrm{C}$ with the plasma power of $150 \mathrm{~W}$. Substrate moving speed is $125 \mathrm{~mm} \mathrm{~s}^{-1}$ and the growth per cycle of spatially-resolved ALD process is $1.0 \AA$ per cycle. Binding energy and atomic concentration of $\mathrm{Al}_{2} \mathrm{O}_{3}$ deposited by spatially-resolved ALD process are shown in Fig. S4.†

\section{Characterizations}

Absorption spectra was taken with a UV/visible spectrophotometer (JASCO, V630). PL emission spectra was obtained by a Cary Eclipse fluorescence spectrophotometer (Agilent Technologies, G9803AA). The diameters of QDs and ZnO NPs were

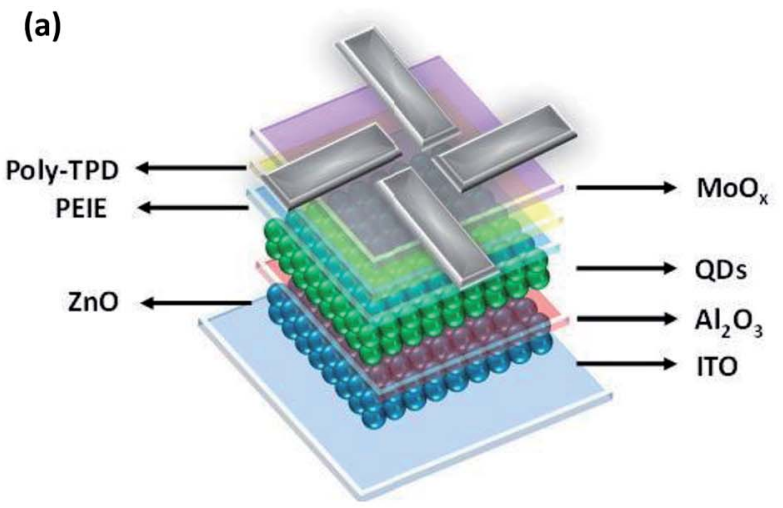

(b)

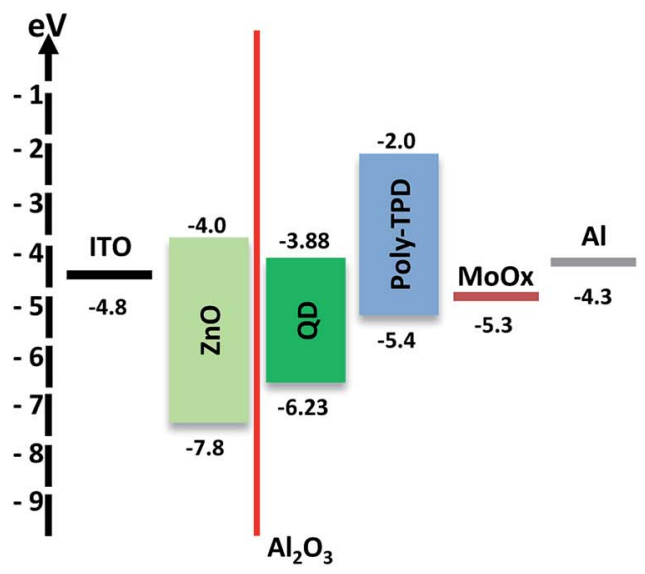

(c)

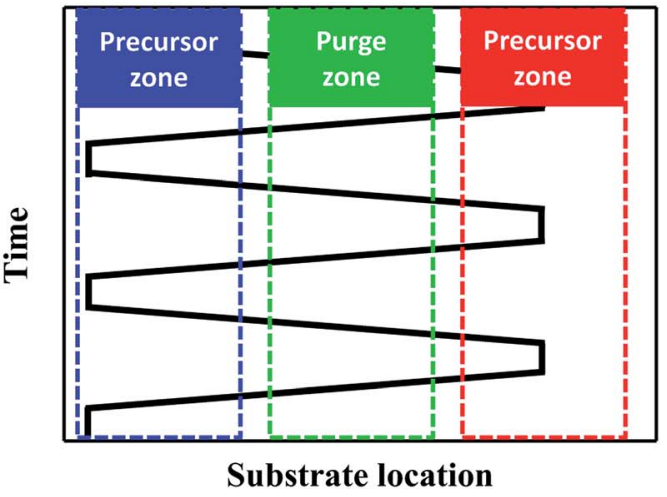

Fig. 1 (a) The schematic structure of the QLED with $\mathrm{Al}_{2} \mathrm{O}_{3}$ interlayer between QDs and $\mathrm{ZnO}$, (b) band energy level diagram of each materials, (c) the schematic view of the sequential procedure of spatiallyresolved ALD process.

determined by a $C_{\mathrm{s}}$-corrected high-resolution transmission electron microscopy (HRTEM) with an accelerating voltage 200 kV (JEOL, JEM-ARM 200F). X-ray diffraction pattern was taken with an X-ray diffractometer (Bruker Corporation, D8 ADVANCE). Surface roughness was measured by highresolution atomic force microscope (SII Nanotechnology, SPA$300 \mathrm{HV}$ ). Band energy levels of each materials were determined using X-ray monochromator (Thermo-Scientific. ESCALAB 250Xi) and UV/visible spectrophotometer. Electrical and optical properties of inverted QLEDs were taken with 

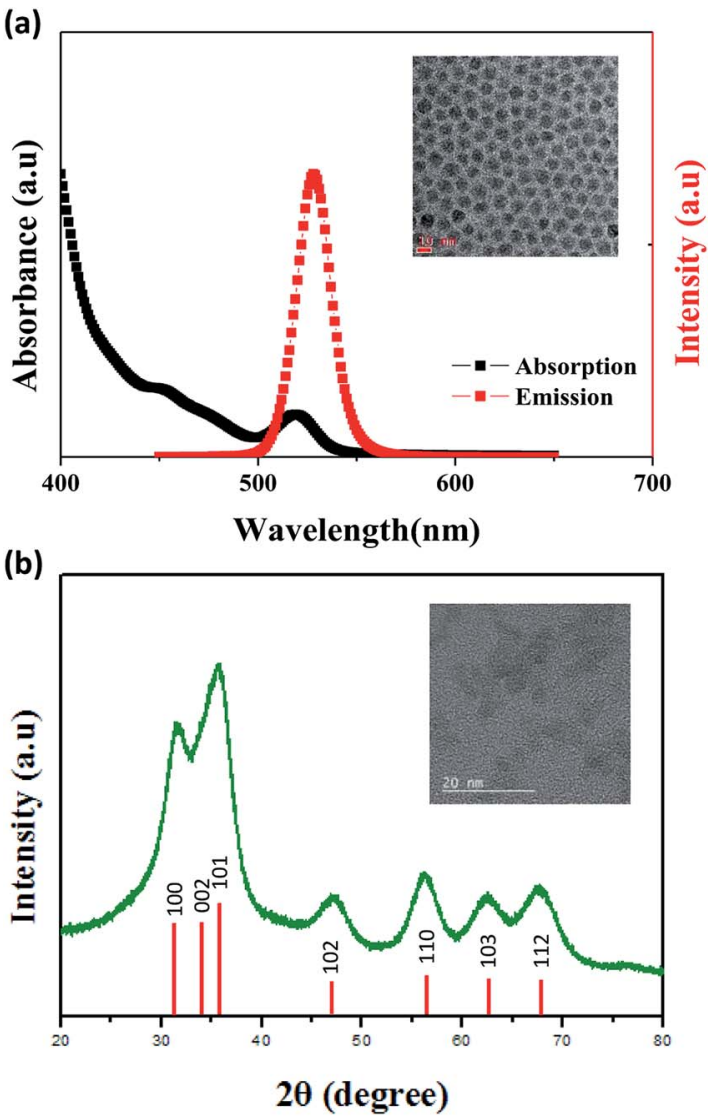

Fig. 2 (a) The absorption and PL spectra of green QDs in hexane/ octane. (inset) TEM image of QDs, (b) X-ray diffraction pattern of $\mathrm{ZnO}$ NPs. (inset) TEM image of ZnO NPs.

spectroradiometer (Konica-Minolta, CS-2000) coupled with a voltage-current source unit (Tektronix, Keithley 2400). Impedance spectra depending on the thickness of the $\mathrm{Al}_{2} \mathrm{O}_{3}$ interlayer was taken with a solar simulator (ABET Technologies, Sun 2000).

\section{Results and discussion}

The device performances of QLEDs are strongly dependent on the QDs qualities, such as quantum yield and size distribution. QDs used in our work are an alloyed core/shell structure QDs with a thick shell for stability ${ }^{28}$ and the absorption and PL spectra of the green QDs used in our work are shown in Fig. 2a. The QDs have an average diameter of $11 \mathrm{~nm}$ (inset Fig. 2a) and a high quantum yield $(\backsim 90 \%)$, which contributes to the fabrication of efficient devices. The uniform distribution of QDs contributes to narrow emission bandwidth which a full width at half maximum (FWHM) is $20 \mathrm{~nm}$ with a peak emission wavelength of QDs at $528 \mathrm{~nm}$ in hexane/octane. The high degree of crystallinity is required for good device performance because the crystallinity of $\mathrm{ZnO}$ NPs is related to electronic properties. ${ }^{4}$ ZnO NPs were synthesized for ETL with the diameter of $3 \mathrm{~nm}$ as shown in inset Fig. 2b, and a well crystallized wurtzite structure (a)

(b)

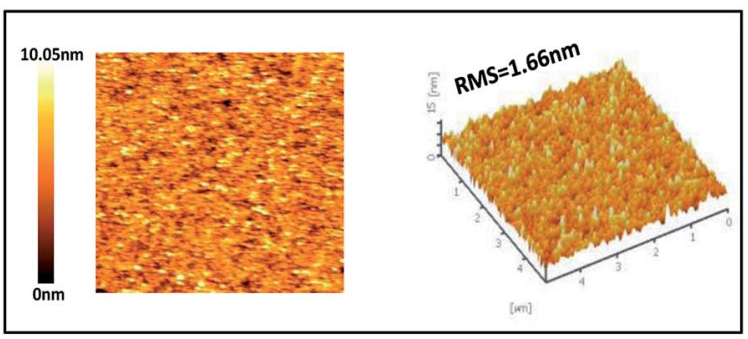

(c)
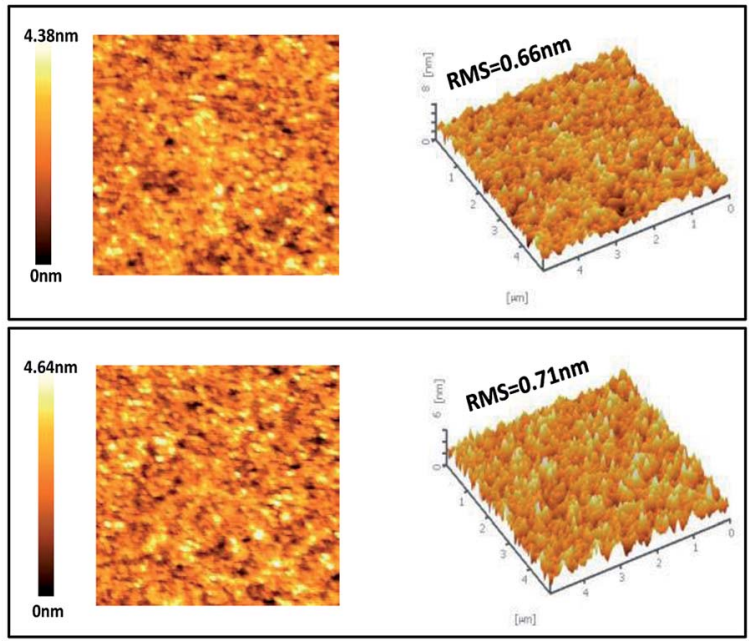

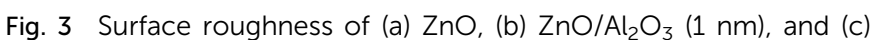
$\mathrm{ZnO} / \mathrm{Al}_{2} \mathrm{O}_{3}(2 \mathrm{~nm})$.

of ZnO NPs was identified by X-ray diffraction pattern as shown in Fig. $2 \mathrm{~b}$.

The smooth underlying layer is required for the uniform QDs layers because the efficiency and stability are strongly dependent on the QDs thickness uniformity. ${ }^{30}$ The surface roughness of $\mathrm{ZnO}$ and $\mathrm{ZnO} / \mathrm{Al}_{2} \mathrm{O}_{3}$ films is shown in Fig. 3. The deposition of the $\mathrm{Al}_{2} \mathrm{O}_{3}$ layer on $\mathrm{ZnO}$ NPs via the ALD process reduced the root-mean squared (RMS) surface roughness to $0.66 \mathrm{~nm}$ of $1 \mathrm{~nm}$ $\mathrm{Al}_{2} \mathrm{O}_{3}$ layer and $0.71 \mathrm{~nm}$ of $2 \mathrm{~nm} \mathrm{Al}_{2} \mathrm{O}_{3}$ layer from $1.66 \mathrm{~nm}$ without the $\mathrm{Al}_{2} \mathrm{O}_{3}$ layer. It has been demonstrated that $\mathrm{Al}_{2} \mathrm{O}_{3}$ could be deposited well on the ZnO NP surface and the reduction of RMS roughness is attributed to the filling of a valley in the $\mathrm{ZnO}$ thin film by the $\mathrm{Al}_{2} \mathrm{O}_{3}$ interlayer. ${ }^{29}$ Smooth surface morphology of the ETL by the $\mathrm{Al}_{2} \mathrm{O}_{3}$ interlayer enables uniform QD thin film deposition and low leakage current in QLEDs, which is critical to improve device performance. ${ }^{23}$ We also measured PL spectra to investigate the effect of $\mathrm{Al}_{2} \mathrm{O}_{3}$ interlayer on non-radiative electron transfer induced by ZnO NPs as shown in Fig. S5. $\dagger^{+14,35,36}$ The $\mathrm{Al}_{2} \mathrm{O}_{3}$ interlayer contributed to preserve fluorescence of QDs by preventing non-radiative electron transfer. The $\mathrm{Al}_{2} \mathrm{O}_{3}$ interlayer serves not only as the electron blocking layer suppressing electron injection but also as a buffer layer preventing electron transfer.

The electrical and optical properties of inverted QLEDs depending on the thickness of the $\mathrm{Al}_{2} \mathrm{O}_{3}$ interlayer (from 0 to 3.0 $\mathrm{nm}$ ) are shown in Fig. 4. The current density of QLEDs was reduced as the thickness of the $\mathrm{Al}_{2} \mathrm{O}_{3}$ interlayer increased, and the reduction of the current density was particularly prominent 
(a)

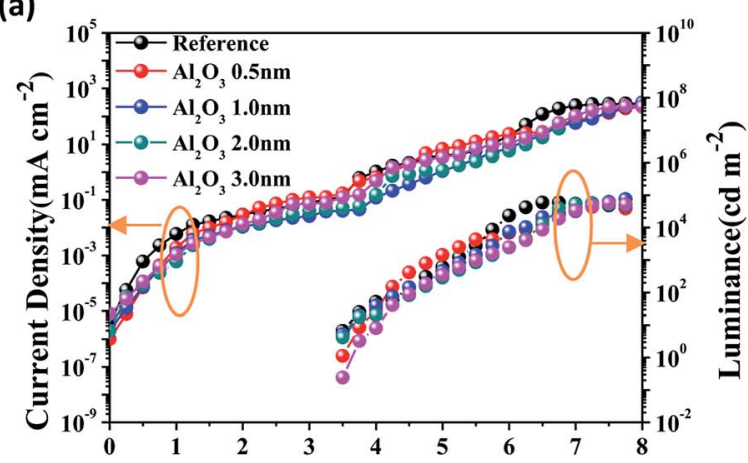

(b)

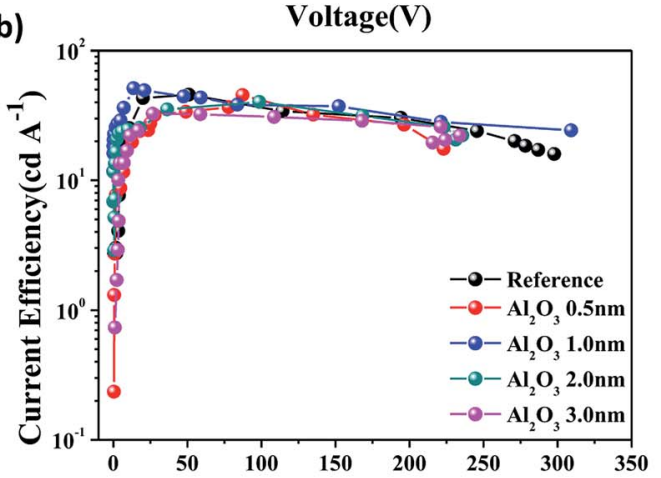

(c)

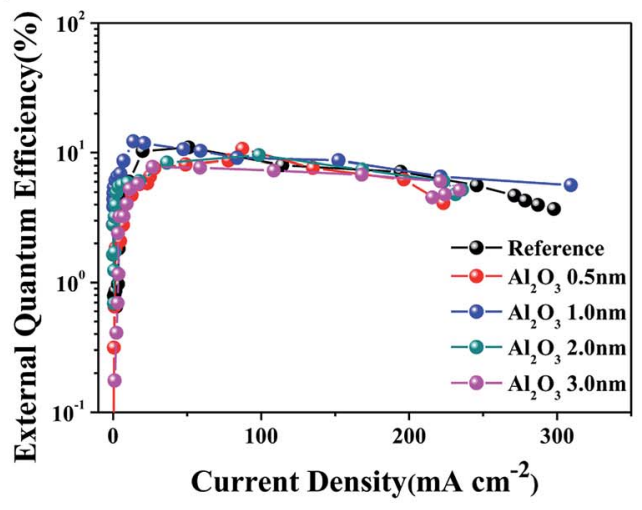

(d)

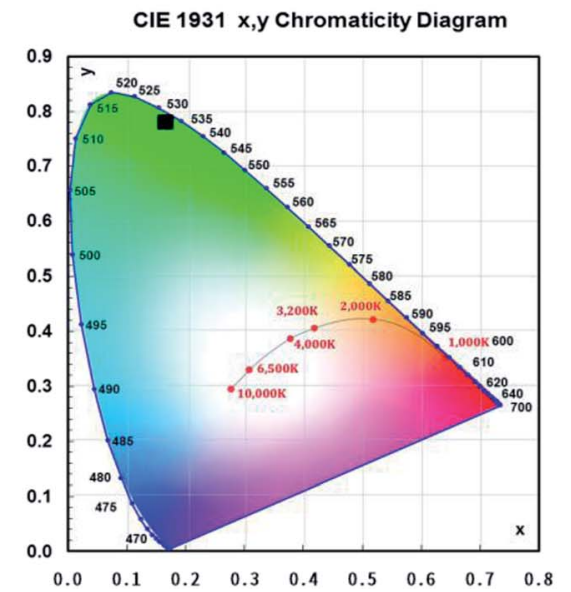

Fig. 4 Optical and electrical properties of QLEDs (a) current densityvoltage and luminance-voltage, (b) current efficiency-current density, (c) external quantum efficiency-current density and (d) $\mathrm{CIE}$ coordinate of the QLEDs with the $1.0 \mathrm{~nm} \mathrm{Al}_{2} \mathrm{O}_{3}$ interlayer.
Table 1 Summarized device performances of QLEDs depending on the thickness of $\mathrm{Al}_{2} \mathrm{O}_{3}$ interlayer

\begin{tabular}{llll}
\hline & $\begin{array}{l}\text { Max. luminance } \\
\left(\mathrm{cd} \mathrm{m}^{-2}\right)\end{array}$ & $\begin{array}{l}\text { Max. current efficiency } \\
\left(\text { cd A }^{-1}\right)\end{array}$ & $\begin{array}{l}\text { Max. EQE } \\
(\%)\end{array}$ \\
\hline Reference & 59000 & 45.8 & 10.9 \\
$\mathrm{Al}_{2} \mathrm{O}_{3}(0.5 \mathrm{~nm})$ & 52800 & 45.3 & 10.7 \\
$\mathrm{Al}_{2} \mathrm{O}_{3}(1.0 \mathrm{~nm})$ & 75100 & 51.2 & 12.2 \\
$\mathrm{Al}_{2} \mathrm{O}_{3}(2.0 \mathrm{~nm})$ & 57600 & 40.2 & 9.5 \\
$\mathrm{Al}_{2} \mathrm{O}_{3}(3.0 \mathrm{~nm})$ & 57100 & 32.6 & 7.8 \\
\hline
\end{tabular}

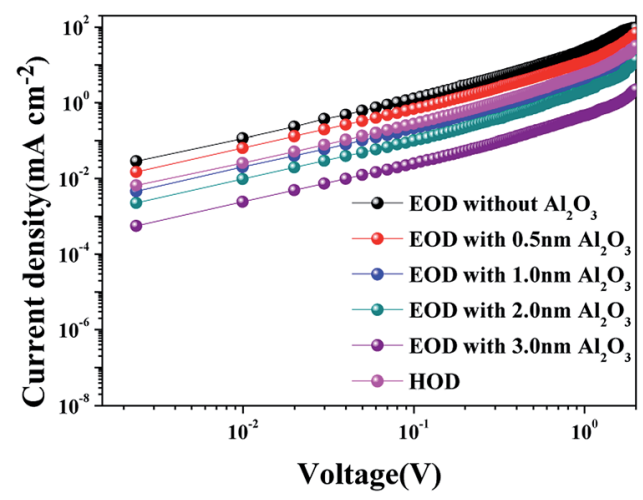

Fig. 5 Current densities of electron only device (EOD, ITO/ZnO/QD/ $\mathrm{ZnO} / \mathrm{Al}$ ) without and with $\mathrm{Al}_{2} \mathrm{O}_{3}$ interlayers, and current density of hole only device (HOD, ITO/poly-TPD/QD/poly-TPD/MoO $/$ /Al).

before a turn-on voltage $(<3.5 \mathrm{~V})$. The turn-on voltage and luminance for the device without the $\mathrm{Al}_{2} \mathrm{O}_{3}$ interlayer are virtually the same as for the device with the $\mathrm{Al}_{2} \mathrm{O}_{3}$ interlayer, whereas the current density is much higher as shown in Fig. 4a. The current efficiency and $\mathrm{EQE}$ with the $1.0 \mathrm{~nm} \mathrm{Al}_{2} \mathrm{O}_{3}$ interlayer show the highest enhancement values compared to those without $\mathrm{Al}_{2} \mathrm{O}_{3}$ interlayer as shown in Fig. $4 \mathrm{~b}$ and $\mathrm{c}$ and the device performances summarized in Table 1. It demonstrates that the $\mathrm{Al}_{2} \mathrm{O}_{3}$ interlayer suppress excessive electron injection due to its insulating property and that charge injection is balanced in the device with the $1.0 \mathrm{~nm} \mathrm{Al}_{2} \mathrm{O}_{3}$ interlayer. On the other hand, the performance with a $0.5 \mathrm{~nm}$ thick $\mathrm{Al}_{2} \mathrm{O}_{3}$ interlayer is nearly identical to that without the $\mathrm{Al}_{2} \mathrm{O}_{3}$ interlayer. It demonstrates that the very thin interlayer hardly interferes with the injection of electrons, even though it is an insulating materials. We are also worth noting that the device performances drastically decreases and the turn-on voltage is delayed when the thickness of the $\mathrm{Al}_{2} \mathrm{O}_{3}$ interlayer is above $3.0 \mathrm{~nm}$ (Fig. S6 $\dagger$ ). The reduction of device performance and the delay of the turn-on voltage are evident when $\mathrm{Al}_{2} \mathrm{O}_{3}$ interlayer is thicker than $5.0 \mathrm{~nm}$ (Fig. S7 $\dagger$ ) and this phenomena can be explained with tunneling effect. ${ }^{31}$ The $\mathrm{Al}_{2} \mathrm{O}_{3}$ interlayer acts as a tunneling barrier, and the tunneling current decreases exponentially as the thickness of the barrier layer increases. ${ }^{32}$ However, in our results, the thickness dependence of the current does not seem to be exponential and this might because the $\mathrm{Al}_{2} \mathrm{O}_{3}$ film on the $\mathrm{ZnO}$ NP film was not continuous film. The optimum thickness of $\mathrm{Al}_{2} \mathrm{O}_{3}$ interlayer is found to be $1.0 \mathrm{~nm}$ and the 1.1-fold 

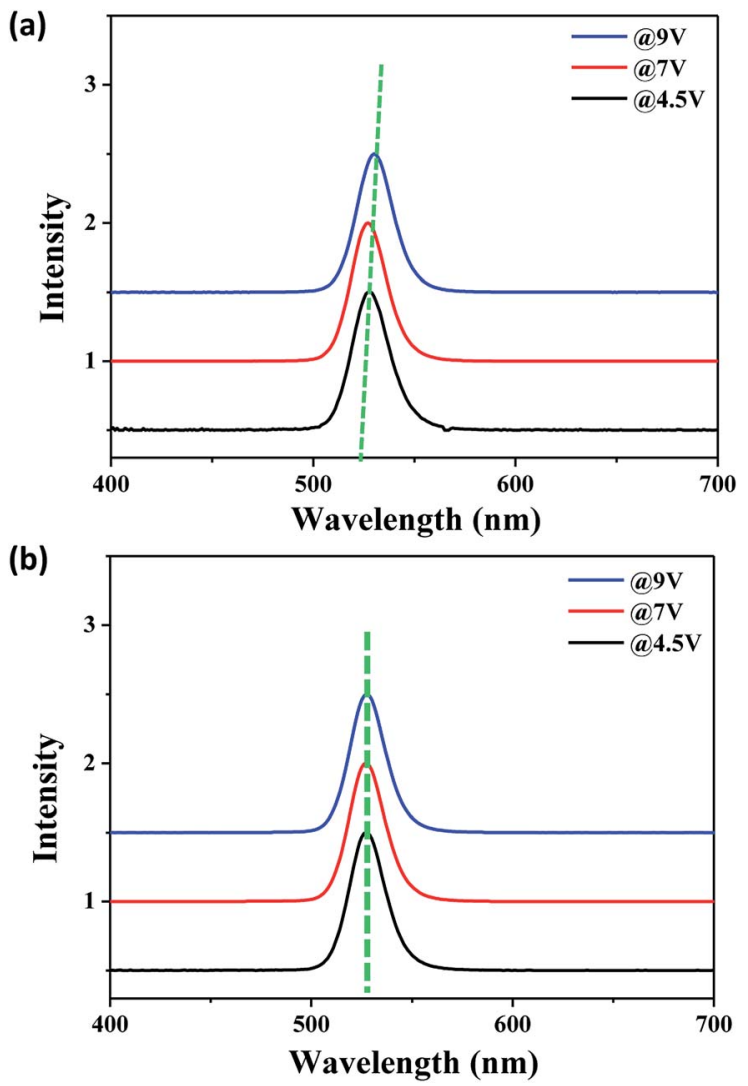

Fig. 6 EL spectra of the devices (a) without and (b) with the $\mathrm{Al}_{2} \mathrm{O}_{3}$ interlayer depending on applied voltages.

improved current efficiency of $51.2 \mathrm{~cd} \mathrm{~A}^{-1}$ and EQE of $12.2 \%$ (average: $9.6 \pm 1.3$ ) were achieved by suppressing excessive electron injection. The EQEs of the 20 unencapsulated QLEDs with the $1.0 \mathrm{~nm} \mathrm{Al}_{2} \mathrm{O}_{3}$ interlayer are summarized in histogram (Fig. $\mathrm{S} 8 \dagger$ ). The device with $\mathrm{Al}_{2} \mathrm{O}_{3}$ interlayer emit deep green light with the Commission International de l'Eclairage (CIE) coordinates of $(0.16,0.78)$ as shown in Fig. $4 \mathrm{~d}$.

The charge balance depending on the thickness of the $\mathrm{Al}_{2} \mathrm{O}_{3}$ interlayer was investigated by electron only (ITO/ZnO/QD/ZnO/ $\mathrm{Al}$ ) and hole only (ITO/poly-TPD/QD/poly-TPD/MoO $/ \mathrm{Al}$ ) devices as shown in Fig. 5. The significantly higher current density is observed in the electron only device without the $\mathrm{Al}_{2} \mathrm{O}_{3}$ interlayer than that of hole only device and this indicates the significant imbalance of charge injection. ${ }^{34}$ The current density of the electron only device with the $0.5 \mathrm{~nm} \mathrm{Al}_{2} \mathrm{O}_{3}$ interlayer is similar to that of the electron only device without the $\mathrm{Al}_{2} \mathrm{O}_{3}$ interlayer. The current density decreases with the increase as $\mathrm{Al}_{2} \mathrm{O}_{3}$ interlayer thickness increases, and the current density of the electron only device is similar to that of hole only device with the $1.0 \mathrm{~nm} \mathrm{Al}_{2} \mathrm{O}_{3}$ interlayer. Charge injection with the $1.0 \mathrm{~nm} \mathrm{Al} \mathrm{Al}_{2}$ interlayer is well balanced and thinner $\mathrm{Al}_{2} \mathrm{O}_{3}$ interlayer hardly affects with electron injection. We also analyzed impedance to elucidate thickness effect of the $\mathrm{Al}_{2} \mathrm{O}_{3}$ interlayer further from electrochemical impedance spectroscopy (EIS). The amplitude of impedance increases drastically and phase angles are in the range of $80-90^{\circ}$ when the thickness (a)

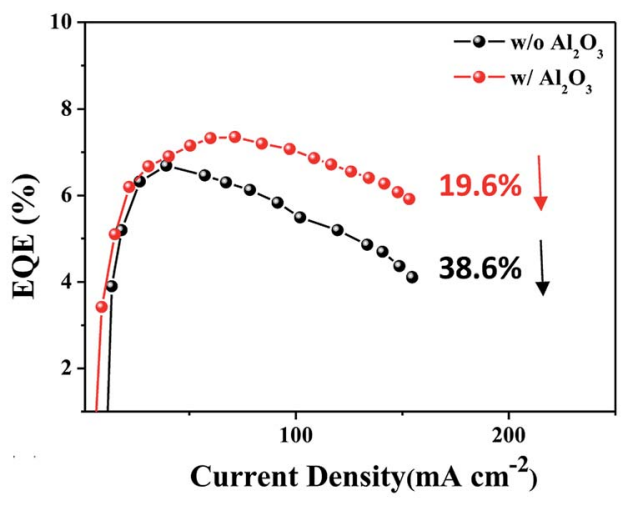

(b)

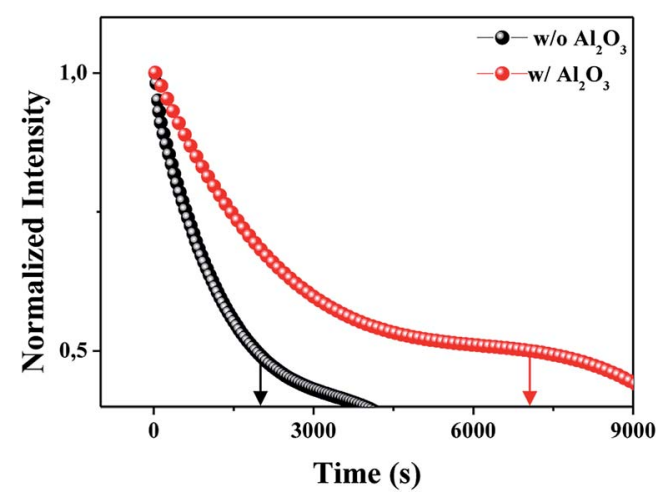

Fig. 7 (a) Efficiency roll-off and (b) device lifetime of QLEDs without and with $\mathrm{Al}_{2} \mathrm{O}_{3}$ interlayer.

of the $\mathrm{Al}_{2} \mathrm{O}_{3}$ interlayer is above $2.0 \mathrm{~nm}$ (Fig. S9†). Both the impedance and the phase angle responses indicate the drastic increase in resistance and capacitance with the $\mathrm{Al}_{2} \mathrm{O}_{3}$ interlayer thicker than $1.0 \mathrm{~nm}$ resulting in the significant suppression of charge injection.

The effect of applied voltage on EL spectra was investigated with and without the $\mathrm{Al}_{2} \mathrm{O}_{3}$ interlayer as shown in Fig. 6. The EL emission of the device with the $\mathrm{Al}_{2} \mathrm{O}_{3}$ interlayer remains unchanged with different applied voltages, whereas the EL emission of the device without the $\mathrm{Al}_{2} \mathrm{O}_{3}$ interlayer shifts to lower energy. The shift of EL emission peak at different applied voltages reflects the operational stability of QLEDs, and this is known to be related to QDs degradation caused by joule heating originated from Auger recombination in QLEDs. ${ }^{99,37}$ The peak shift of EL emission indicates that the insulating $\mathrm{Al}_{2} \mathrm{O}_{3}$ interlayer also improves the stability of EL emission by suppressing the joule heating.

We investigated efficiency roll-off that can be an indicator of the exciton quenching by Auger recombination on the QLEDs as shown in Fig. $7 \mathrm{a}^{19}$ The efficiency roll-off of $38.6 \%$ at $150 \mathrm{~mA}$ $\mathrm{cm}^{-2}$ was observed without the $\mathrm{Al}_{2} \mathrm{O}_{3}$ interlayer and $19.6 \%$ observed with the $\mathrm{Al}_{2} \mathrm{O}_{3}$ interlayer. The EQE with the $\mathrm{Al}_{2} \mathrm{O}_{3}$ interlayer was also maintained higher than that without $\mathrm{Al}_{2} \mathrm{O}_{3}$ interlayer throughout the entire experimental current density range. Device lifetime was monitored as shown in Fig. $7 \mathrm{~b}$ and also improved by the $\mathrm{Al}_{2} \mathrm{O}_{3}$ interlayer since the exciton quenching, such as Auger recombination, was suppressed by 
interfering with excess electron injection. The devices were tested with a constant driving current density $\left(10 \mathrm{~mA} \mathrm{~cm}{ }^{-2}\right)$ without encapsulation for the lifetime measurement. The lifetime is defined here with the time for the initial luminance to reduce to half. Initial luminance was 2600 and $1750 \mathrm{~cd} \mathrm{~m}^{-2}$ with and without the $\mathrm{Al}_{2} \mathrm{O}_{3}$ interlayer, respectively. The device with the $\mathrm{Al}_{2} \mathrm{O}_{3}$ interlayer shows the device half lifetime of $7070 \mathrm{~s}$, which improved by 3 -fold as compared to $2030 \mathrm{~s}$ for the device without the $\mathrm{Al}_{2} \mathrm{O}_{3}$ interlayer. The half lifetime can be converted into the lifetime at $100 \mathrm{~cd} \mathrm{~m}^{-2}$ with the following relation. ${ }^{38}$

$$
L_{0}^{\mathrm{n}} T_{50}=\text { constant }(n=1.5)
$$

At luminance of $100 \mathrm{~cd} \mathrm{~m}^{-2}$, the device lifetime is about $42 \mathrm{~h}$ and $260 \mathrm{~h}$ for the devices without and with $\mathrm{Al}_{2} \mathrm{O}_{3}$ interlayer, respectively. The device lifetime with the $\mathrm{Al}_{2} \mathrm{O}_{3}$ interlayer is improved about 6 times than the device without the $\mathrm{Al}_{2} \mathrm{O}_{3}$ interlayer.

\section{Conclusions}

We deposited a $1.0 \mathrm{~nm}$ thick $\mathrm{Al}_{2} \mathrm{O}_{3}$ interlayer by an ALD process between EML and ETL of inverted QLED. The ALD process enables precise thickness control in the atomic scale. The $1.0 \mathrm{~nm}$ thick $\mathrm{Al}_{2} \mathrm{O}_{3}$ interlayer improves the charge balance in the device and the device with the interlayer exhibited device performances of $51.2 \mathrm{~cd} \mathrm{~A}^{-1}$ in current efficiency and $12.2 \%$ in EQE. The efficiency roll-off was suppressed from $38.6 \%$ to $19.6 \%$ at current density up to $150 \mathrm{~mA} \mathrm{~cm}{ }^{-2}$ and the device lifetime increased about 6 times than the device without $\mathrm{Al}_{2} \mathrm{O}_{3}$ interlayer. The $\mathrm{Al}_{2} \mathrm{O}_{3}$ interlayer as a tunneling barrier reduces leakage current of the device and improves radiative recombination in the EML by suppressing Auger recombination and non-radiative electron transfer induced by ZnO NPs. This work demonstrates for the first time within our knowledge in the inverted QLEDs that the $\mathrm{Al}_{2} \mathrm{O}_{3}$ interlayer is a promising candidate for charge control and paves a reliable way for fabricating the efficient and stable devices.

\section{Conflicts of interest}

There are no conflicts to declare.

\section{Acknowledgements}

This research was supported by the Global Frontier R\&D Program on Center for Multiscale Energy System funded by the National Research Foundation under the Ministry of Science, ICT \& Future Planning, Korea (2012M3A6A7054855). This work was supported by the National Research Foundation of Korea (NRF) grant funded by the Korea government (MSIT) (2018R1A2A3074950).

\section{Notes and references}

1 P. O. Anikeeva, J. E. Halpert, M. G. Bawendi and V. Bulovic, Nano Lett., 2009, 9, 2532.

2 J. Zhao, J. A. Bardecker, A. M. Munro, M. S. Liu, Y. Niu, I. K. Ding, J. Luo, B. Chen, A. K. Y. Jen and D. S. Ginger, Nano Lett., 2006, 6, 463-467.

3 D. V. Talapin, J. Lee, M. V. Kovalenko and E. V. Shevchenko, Chem. Rev., 2010, 110, 389-458.

4 L. Qian, Y. Zheng, J. Xue and P. H. Holloway, Nat. Photonics, 2011, 5, 543-548.

5 H. J. Yun, T. Paik, M. E. Edley, J. B. Baxter and C. B. Murray, ACS Appl. Mater. Interfaces, 2014, 6, 3721-3728.

6 H. Y. Yang, Y. Fu, M. S. Jang, Y. Li, J. H. Lee, H. Chae and D. S. Lee, ACS Appl. Mater. Interfaces, 2016, 8, 35021-35032.

7 J. W. Stouwdam and R. A. J. Janssen, J. Mater. Chem., 2008, 18, 1889-1894.

8 N. Kim, W. Na, W. Yin, H. Jin, T. K. Ahn, S. M. Cho and H. Chae, J. Mater. Chem. C, 2016, 4, 2457-2462.

9 B. Mashford, M. Stevenson, Z. Popovic, C. Hamilton, Z. Zhou, C. Breen, J. Steckel, V. Bulovic, M. Bawendi, S. Coe-Sullivan and P. T. Kazlas, Nat. Photonics, 2013, 7, 407-412.

10 Y. Fu, D. Kim, H. Moon, H. Yang and H. Chae, J. Mater. Chem. C, 2017, 5, 522.

11 J. Pan, J. Chen, Q. Huang, Q. Khan, X. Liu, Z. Tao, Z. Zhang, W. Lei and A. Nathan, ACS Photonics, 2016, 3, 215-222.

12 H. M. Kim, D. Geng, J. Kim, E. Hwang and J. Jang, ACS Appl. Mater. Interfaces, 2016, 8, 28727-28736.

13 G. Zaiats, S. Ikeda, S. Kinge and P. V. Kamat, ACS Appl. Mater. Interfaces, 2017, 9, 30741-30745.

14 X. Dai, Z. Zhang, Y. Jin, Y. Niu, H. Cao, X. Liang, X. Chen, J. Wang and X. Peng, Nature, 2014, 515, 96-99.

15 D. Kim, Y. Fu, S. Kim, W. Lee, K. H. Lee, H. K. Chung, H. J. Lee, H. Yang and H. Chae, ACS Nano, 2017, 11, 19821990.

16 K. H. Lee, J. H. Lee, W. S. Song, H. Ko, C. Lee, J. H. Lee and H. Yang, ACS Nano, 2013, 7, 7295-7302.

17 Q. Lin, L. Wang, Z. Li, H. Shen, L. Guo, Y. Kuang, H. Wang and L. S. Li, ACS Photonics, 2018, 5, 939-946.

18 V. I. Klimov, A. A. Mikhailovsky, D. W. McBranch, C. A. Leatherdale and M. G. Bawendi, Science, 2000, 287, 1011-1013.

19 W. K. Bae, Y. S. Park, J. Lim, D. Lee, L. A. Padilha, H. McDaniel, I. Robel, C. Lee, J. M. Pietryga and V. I. Klimov, Nat. Commun., 2013, 7, 9019-9026.

20 W. K. Bae, S. Brovelli and V. I. Klimov, MRS Bull., 2013, 38, 721-730.

21 J. Kwak, J. Lim, M. Park, S. Lee, K. Char and C. Lee, Nano Lett., 2015, 15, 3793-3799.

22 P. Rastogi, F. Palazon, M. Prato, F. Di Stasio and R. Krahne, ACS Appl. Mater. Interfaces, 2018, 10, 5665-5672.

23 A. Castelli, F. Meinardi, M. Pasini, F. Galeotti, V. Pinchetti, M. Lorenzon, L. Manna, I. Moreels, U. Giovanella and S. Brovelli, Nano Lett., 2015, 15, 5455. 
24 K. Ding, H. Chen, L. Fan, B. Wang, Z. Huang, S. Zhuang, B. Hu and L. Wang, ACS Appl. Mater. Interfaces, 2017, 9, 20231-20238.

25 H. Zhang, N. Sui, X. Chi, Y. Wang, Q. Liu, H. Zhang and W. Ji, ACS Appl. Mater. Interfaces, 2016, 8, 31385-31391.

26 Y. Q. Yang, Y. Duan, P. Chen, F. B. Sun, Y. H. Duan, X. Wang and D. J. Yang, J. Phys. Chem. C, 2013, 117, 20308-20312.

27 Y. Duan, F. Sun, Y. Yang, P. Chen, D. Yang, Y. Duan and X. Wang, ACS Appl. Mater. Interfaces, 2014, 6, 3799-3804.

28 Y. Fu, D. Kim, W. Jiang, W. Yin, T. K. Ahn and H. Chae, RSC Adv., 2017, 7, 40866-40872.

29 J.-H. Choi, J. Kim, S. J. Oh, D. Kim, Y.-H. Kim, H. Chae and H. Kim, Met. Mater. Int., 2016, 22, 723-729.

30 H. M. Kim, J. H. Youn, G. J. Seo and J. Jang, J. Mater. Chem. C, 2013, 1, 1567-1573.

31 H. A. Al Attar and A. P. Monkman, Adv. Funct. Mater., 2006, 16, 2231-2242.

32 Y. E. Kim, H. Park and J. J. Kim, Appl. Phys. Lett., 1996, 69, 599-601.
33 Y. Zhou, C. Fuentes-Hernandez, J. Shim, J. Meyer, A. J. Giordano, H. Li, P. Winget, T. Papadopoulos, H. Cheun, J. Kim, M. Fenoll, A. Dindar, W. Haske, E. Najafabadi, T. M. Khan, H. Sojoudi, S. Barlow, S. Graham, J. L. Bredas, S. R. Marder, A. Kahn and B. Kippelen, Science, 2012, 336, 327-332.

34 J. Li, Z. Liang, Q. Su, H. Jin, K. Wang, G. Xu and X. Xu, ACS Appl. Mater. Interfaces, 2018, 10, 3865-3873.

35 K. Tvrdy, P. A. Frantsuzov and P. V. Kamat, Proc. Natl. Acad. Sci. U. S. A., 2011, 108, 29-34.

36 V. Wood, M. J. Panzer, L. E. Halpert, J. M. Caruge, M. G. Bawendi and V. Bulovic, ACS Nano, 2009, 3, 3581-3586. 37 S. Shendre, V. K. Sharma, C. Dang and H. V. Demir, ACS Photonics, 2018, 5, 480-486.

38 P. Wellmann, M. Hofmann, O. Zeika, A. Werner, J. Birnstock, R. Meerheim, G. He, K. Walzer, M. Pfeiffer and K. Leo, J. Soc. Inf. Disp, 2005, 13, 393-397. 